\title{
Transmission of Chikungunya Virus in an Urban Slum, Brazil
}

\author{
Rosângela O. Anjos, Vánio André Mugabe, Patrícia S.S. Moreira, Caroline X. Carvalho, \\ Moyra M. Portilho, Ricardo Khouri, Gielson A. Sacramento, Nivison R.R. Nery Jr., \\ Mitermayer G. Reis, Uriel D. Kitron, Albert I. Ko, Federico Costa, Guilherme S. Ribeiro
}

\begin{abstract}
After a chikungunya outbreak in Salvador, Brazil, we performed a cross-sectional, community-based study of 1,776 inhabitants to determine chikungunya virus (CHIKV) seroprevalence, identify factors associated with exposure, and estimate the symptomatic infection rate. From November 2016 through February 2017, we collected sociodemographic and clinical data by interview and tested serum samples for CHIKV IgG. CHIKV seroprevalence was $11.8 \%$ (95\% Cl $9.8 \%-13.7 \%$ ), and $15.3 \%$ of seropositive persons reported an episode of fever and arthralgia. Infections were independently and positively associated with residences served by unpaved streets, a presumptive clinical diagnosis of chikungunya, and recall of an episode of fever with arthralgia in 2015-2016. Our findings indicate that the chikungunya outbreak in Salvador may not have conferred sufficient herd immunity to preclude epidemics in the near future. The unusually low frequency of symptomatic disease points to a need for further longitudinal studies to better investigate these findings.
\end{abstract}

Tn the 21st century, chikungunya virus (CHIKV) Lhas emerged as a mosquitoborne disease of global relevance, causing large epidemics because of its widespread dissemination in tropical and subtropical areas (1). Infected persons usually develop an acute febrile illness associated with joint pains, myalgia, headache, and other signs and symptoms that can

Author affiliations: Fundação Oswaldo Cruz, Salvador, Brazil

(R.O. Anjos, P.S.S. Moreira, C.X. Carvalho, M.M. Portilho, R. Khouri,

G.A. Sacramento, N.R.R. Nery Jr., M.G. Reis, U.D. Kitron, A.I. Ko,

F. Costa, G.S. Ribeiro); Universidade Licungo, Quelimane,

Mozambique (V.A. Mugabe); Universidade Federal da Bahia,

Salvador (V.A. Mugabe, R. Khouri, N.R.R. Nery Jr., M.G. Reis,

F. Costa, G.S. Ribeiro); Yale University, New Haven, Connecticut,

USA (M.G. Reis, A.I. Ko, F. Costa); Emory University, Atlanta,

Georgia, USA (U.D. Kitron); University of Liverpool, Liverpool, UK

(F. Costa); Lancaster University, Lancaster, UK (F. Costa)

DOI: https://doi.org/10.3201/eid2607.190846 lead to misdiagnosis with other arboviral illnesses, such as dengue virus (DENV) and Zika virus (ZIKV) infections. Noteworthy with chikungunya, the arthralgia is often severely debilitating and may last for months to years $(1,2)$.

After the introduction of CHIKV into the Caribbean region in 2013, the virus spread rapidly, causing large outbreaks $(3,4)$. In certain Caribbean islands, such as Puerto Rico and the US Virgin Islands, the rate at which CHIKV infection was symptomatic was estimated at $>70 \%(5,6)$. However, it remains unclear whether the attack rates in outbreaks in large population centers in the Americas created sufficiently high levels of herd immunity to preclude subsequent epidemics. Furthermore, 2 CHIKV strains were introduced and are cocirculating in the Americas; it is unclear whether the proportions of symptomatic infections differ on the basis of strain type, population, or region.

In Brazil, CHIKV was first detected in September 2014, almost simultaneously in the cities of Oiapoque, in the northern state of Amapá, where the Asian genotype was implicated (7), and in Feira de Santana, in the northeast state of Bahia, where the East/Central/ South African (ECSA) genotype was detected $(7,8)$. The virus spread rapidly throughout the country, reaching all states by 2015 (9), and peaked in 2016, when $\approx 280,000$ probable cases were recorded (10). The northeast region was the most affected by CHIKV $(9,10,11)$; this same area was also the most affected by ZIKV in 2015-2016 (12,13).

In Salvador (population 2.9 million [14]), the capital of Bahia state, which is located $\approx 100 \mathrm{~km}$ from Feira de Santana, we retrospectively identified that CHIKV had been circulating since September 2014 (15), but outbreaks first occurred between June and November $2015(12,15)$. In this study, we used the prevalence of CHIKV IgG as an indicator of all (i.e., symptomatic and asymptomatic) previous infection in a slum 
community of Salvador and assessed the proportion of cases in which these infections were symptomatic. In addition, we investigated factors potentially associated with prior CHIKV infection.

\section{Methods}

\section{Study Site and Participant Selection}

We performed a cross-sectional study in Pau da Lima, a poor community in Salvador characterized by high population density and substandard sanitation infrastructure $(16,17)$. Since 2003 , this community has been the site for several studies aiming to determine the epidemiology and the transmission dynamics of leptospirosis (17-19), dengue, and other arboviral diseases $(15,16,20,21)$, as well as the burden of chronic noncommunicable diseases on the community and its residents $(22,23)$. Detailed information about the sociodemographics of the Pau da Lima community, environment, and urban infrastructure has been previously described in these studies.

We surveyed the residents of 3 contiguous valleys in Pau da Lima from November 2016 through February 2017. During the enrollment process, we visited all households in the study site and invited all residents $\geq 5$ years of age who slept $\geq 3$ nights per week in the house to participate.

\section{Data Collection}

We used a standardized questionnaire during household visits to obtain data on participant demographic and socioeconomic conditions. Data collected were age, sex, self-reported skin color, education level, occupation or work, household per capita income, material of housing walls (wood or other material that is not brickwork, plastered or not plastered), quality of streets accessing house (paved or unpaved), and number of residents per household (Appendix, https:/ / wwwnc.cdc.gov/EID/article/26/7/19-0846-App1. pdf). We also collected self-reported data on prior presumptive clinical diagnosis of DENV, ZIKV, and CHIKV infection and on history of fever, arthralgia, myalgia, rash, and pruritus, at any time after January 2015. This information covered health effects from the period immediately before and after the peak of CHIKV transmission in Salvador, which occurred during June-November 2015 (12,15). We recorded the duration of arthralgia among participants who reported this symptom. We conducted the interviews on computer tablets and used Research Electronic Data Capture software (REDCap; https:/ / projectredcap.org/software/) to store the data (24).

\section{Serologic Evaluation}

During the household visits, we collected $10 \mathrm{~mL}$ of blood from each participant and transported the samples on the same day, stored at $2^{\circ} \mathrm{C}-8^{\circ} \mathrm{C}$, to our laboratory at the Instituto Gonçalo Moniz, Fundação Oswaldo Cruz, in Salvador. We centrifuged the samples to obtain serum, which we aliquoted and stored at $-20^{\circ} \mathrm{C}$ until evaluation. We tested serum samples by using the IgG ELISA technique (Euroimmun, https:/ / www.euroimmun.com) to detect specific CHIKV IgG.

For samples showing positive results for IgG, we then tested with a CHIKV IgM ELISA (InBios, https:/ /inbios.com); we used the presence of IgM as a proxy for a more recent $\mathrm{CHIKV}$ infection than if there were no IgM. We interpreted both the CHIKV IgG and IgM ELISA results according to manufacturer instructions: CHIKV IgG absorbance/calibrator levels were negative at $<0.8$, indeterminate at $\geq 0.8$ to $<1.1$, and positive at $\geq 1.1$; CHIKV IgM absorbance/calibrator levels were negative at $<0.9$, indeterminate at $\geq 0.9$ to $<1.1$, and positive at $\geq 1.1$. We retested samples indicating indeterminant results on the initial test and considered the results obtained final.

To confirm the accuracy of results from the IgG ELISA, we performed a blind plaque-reduction neutralization test (PRNT) of a stratified random sample of 60 serum samples ( 30 positive and 30 negative from the CHIKV IgG ELISA) for CHIKV to determine $\geq 90 \%$ reductions in plaque counts $\left(\mathrm{PRNT}_{90}\right)$, as described elsewhere (25). To investigate whether cryoglobulinemia could have reduced the sensitivity of the IgG ELISA, we retested 100 samples, randomly selected from those that had been IgG negative, using a prewarmed $\left(2 \mathrm{~h}\right.$ at $\left.37^{\circ} \mathrm{C}\right)$ and centrifuge protocol (26).

\section{Data Analysis}

We used absolute and relative frequencies or medians and interquartile ranges (IQR) to characterize the sociodemographics and also reported presumptive diagnoses and history of symptoms of study participants. We used $\chi^{2}$ or Wilcoxon rank-sum tests to compare the sex and age distribution for those who did agree to be enrolled in the study with the distribution for those who did not. We used a 2-tailed $p$ value of $<0.05$ to define statistically significant differences.

We calculated the prevalence of CHIKV IgG overall and according to participants' characteristics and categorized continuous variables so we could estimate CHIKV seroprevalence by groups. We stratified age into ranges of 5-14 years, 15-39 years, and $\geq 40$ years to account for the disproportionately young average age of the sample; we characterized education level as illiterate for participants who had 
never studied and literate for participants who had studied $\geq 1$ year. We determined those living in poverty using the World Bank's criteria for poverty in upper-middle-income countries of $\leq \$ 5.50 /$ day (US dollars) per capita household income (27). We obtained $95 \%$ CIs for the prevalence measures, adjusting them for the design effect of sampling households as clusters.

We used bivariate and multivariate Poisson regression models with robust variance and adjustment for design effect to verify associations between previous CHIKV infection and the sociodemographic and clinical characteristics of participants. We calculated prevalence ratios with 95\% CIs and included all variables that had bivariate analyses with a $p$ value $<0.20$ in the multivariate analyses. We then used a backward selection method to build 2 final multivariate models, retaining variables with a $p$ value $<0.05$. The first model included only sociodemographic variables to investigate their role in CHIKV infection, whereas the second model included only clinical characteristics to address their capacity to predict a positive serologic result.

Among the participants with a positive CHIKV IgG ELISA, we estimated the frequencies of symptomatic CHIKV infection by calculating the proportion of those who reported fever simultaneously accompanied by arthralgia after January 2015, likely recent CHIKV infection by calculating the proportion of those with a positive IgM test result, and presumptive clinical suspicion of chikungunya by calculating the proportion of those who reported having received that diagnosis. Wilcoxon rank-sum test was used to compare the median duration of arthralgia between those reporting arthralgia accompanied by fever and those reporting only arthralgia. Poisson regression models with robust variance, adjusted for design effect, were used to compare sociodemographic and clinical characteristics between participants with symptomatic CHIKV infections and those with asymptomatic infections and between participants with likely recent and those with likely nonrecent CHIKV infections. We set a two-tailed $p$ value $<0.05$ to define statistically significant differences. We performed data analysis using Stata version 14 software (StataCorp, https:/ / www.stata.com) (28).

\section{Ethics Considerations}

This study was approved by the Research Ethics Committee of Gonçalo Moniz Institute, Oswaldo Cruz Foundation (CAAE $n^{\circ}$ 55904616.4.0000.0040). Before any study procedure, all participants $\geq 18$ years of age signed an informed consent form; those $<18$ years of age who were able to read signed an informed assent, with their parents providing a signed consent.

\section{Results}

\section{Participants Characteristics}

Among the 2,651 eligible residents in the study site, $1,776(67.0 \%)$ agreed to participate in this study. Those who consented were younger than those who refused (median age 26 years [IQR 16-40] vs. 35 years [IQR 21-46]; $p$ <0.01). Of those who consented, a greater proportion were female $(57.0 \%)$ than those who did not consent $(52.0 \% ; \mathrm{p}<0.01)$. Most participants had a nonwhite (black or mixed) skin color $(93.8 \%)$, lived in a household with a per capita income $\leq \$ 5.50 /$ day (US dollars) $(80.8 \%)$, and had not completed elementary school education $(59.0 \%)$ or were illiterate $(4.3 \%)$.

\section{Prevalence of Previous CHIKV Infection and Associated Factors}

Among the 1,772 (99.8\%) participants from whom we collected and tested a blood sample, 209 (11.8\%, 95\% CI $9.8 \%-13.7 \%$ ) had had a previous CHIKV infection, as determined by the detection of CHIKV IgG. Of the 30 random IgG ELISA positive samples tested by CHIKV PRNT ${ }_{90}, 27$ (90\%) were positive; of the 30 random IgG-negative samples, all were also negative in $\mathrm{PRNT}_{90}$ (agreement 95\%; kappa 90\%). Of the 100 IgG-negative samples that we retested to evaluate whether cryoglobulinemia had reduced ELISA sensitivity, $2(2 \%)$ returned positive results, but these results had low absorbance/calibrator levels (1.11 and 1.15) compared with those observed for the 209 positive samples (median 3.53, IQR 3.11-3.82).

In bivariate analyses, prevalence of previous CHIKV infection did not differ by sex, skin color, poverty level, or number of residents per household (Table 1). However, we found a statistically significant association with other indicators of socioeconomic status, residing on unpaved streets and living in houses whose walls were unplastered or were made of wood or other materials; in addition, we found a nonsignificant trend of greater prevalence among participants who were older, illiterate, or reported not working (Table 1). Furthermore, the prevalence of previous CHIKV infection was statistically greater for participants who had received a presumptive clinical diagnosis of an infection by any of 3 cocirculating arboviruses-CHIKV, DENV, or ZIKV - and for those who reported having symptoms compatible with an arboviral infection-fever with arthralgia, myalgia, rash, or pruritus - after January 2015, when CHIKV emerged in Salvador (Table 1). 
The only sociodemographic characteristic associated with previous CHIKV infection in the multiple variable analyses was residence on an unpaved street (prevalence ratio [PR] 1.52, 95\% CI 1.07-2.15) (Table
2). In addition, independent clinical predictors for previous CHIKV infection included recall of a presumptive medical diagnosis of chikungunya (PR 2.83, 95\% CI 1.97-4.05) and report of an episode of fever

Table 1. Prevalence of previous chikungunya virus infection, determined by detection of IgG, by demographic and clinical characteristics, Salvador, Brazil, November 2016-February 2017

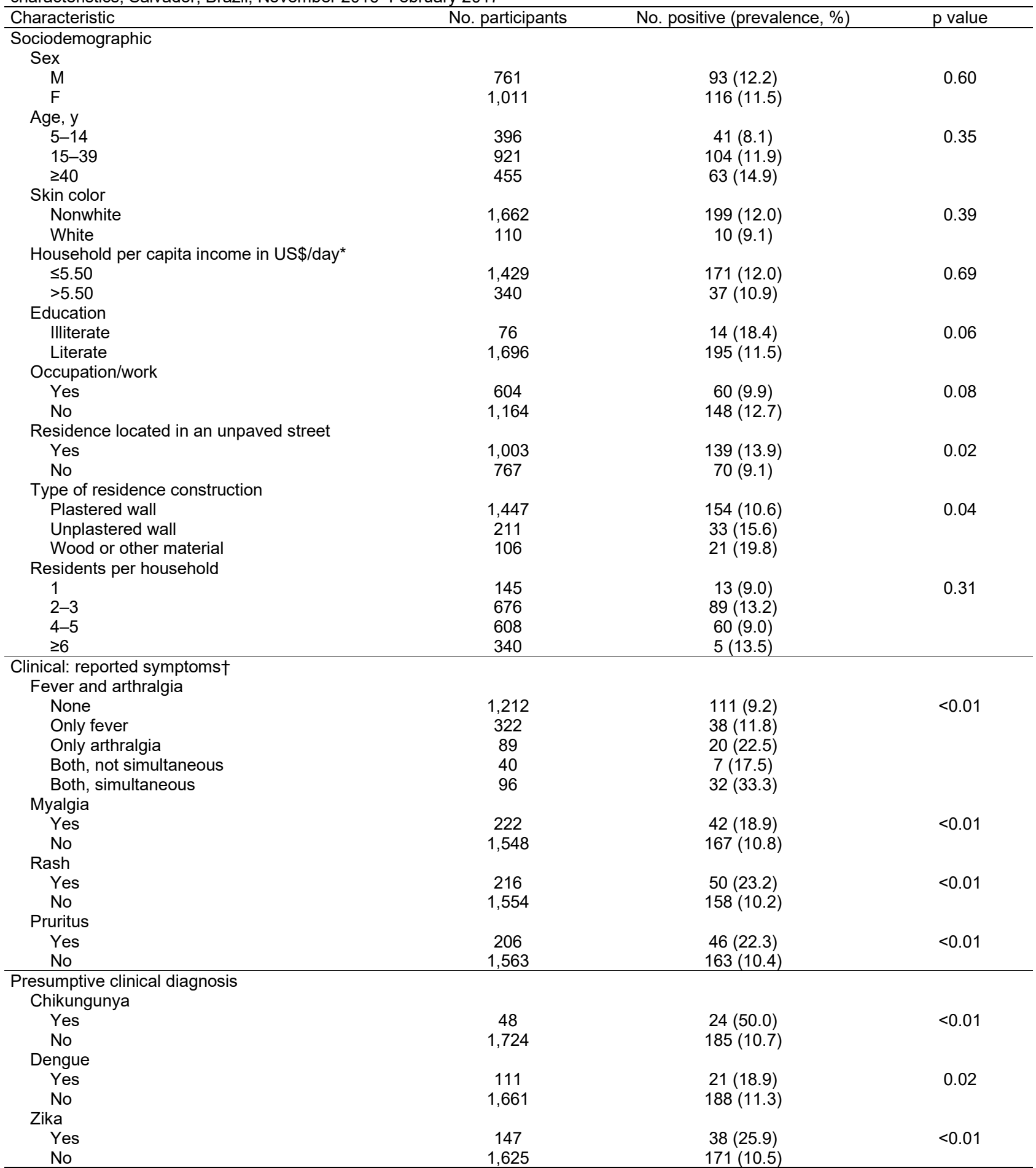

*Data not shown for 3 participants.

†Reported symptoms with onset after January 2015. 
Table 2. Crude and adjusted prevalence ratios for persons with previous chikungunya virus infection, by demographic and clinical characteristics, Salvador, Brazil, November 2016-February 2017

\begin{tabular}{|c|c|c|}
\hline Characteristic & Crude prevalence ratio $(95 \% \mathrm{Cl})^{*}$ & Adjusted prevalence ratio $(95 \% \mathrm{Cl}) \dagger$ \\
\hline Sociodemographic & & Model 1 \\
\hline Illiteracy & $1.60(0.99-2.60)$ & \\
\hline Not working & $1.28(0.97-1.68)$ & \\
\hline Residence located in an unpaved street & $1.52(1.07-2.15)$ & $1.52(1.07-2.15)$ \\
\hline \multicolumn{3}{|l|}{ Type of residence construction } \\
\hline Plastered wall & Referent & \\
\hline Unplastered wall & $1.47(0.92-2.35)$ & \\
\hline Wood/Other material & $1.86(1.06-3.28)$ & \\
\hline Clinical: reported symptoms $\ddagger$ & & Model 2 \\
\hline \multicolumn{3}{|l|}{ Fever and arthralgia } \\
\hline None & Referent & Referent \\
\hline Only fever & $1.29(0.89-1.86)$ & $0.96(0.62-1.49)$ \\
\hline Only arthralgia & $2.45(1.60-3.75)$ & $1.55(0.95-2.53)$ \\
\hline Both, not simultaneous & $1.91(0.97-3.77)$ & $1.22(0.56-2.67)$ \\
\hline Both, simultaneous & $3.64(2.51-5.28)$ & $2.26(1.43-3.57)$ \\
\hline Myalgia & $1.75(1.23-2.50)$ & \\
\hline Rash & $2.28(1.68-3.08)$ & \\
\hline Pruritus & $2.14(1.51-3.03)$ & \\
\hline \multicolumn{3}{|l|}{ Presumptive clinical diagnosis } \\
\hline Chikungunya & $4.66(3.35-6.48)$ & $2.83(1.97-4.05)$ \\
\hline Dengue & $1.67(1.09-2.56)$ & \\
\hline Zika & $2.45(1.78-3.39)$ & \\
\hline
\end{tabular}

with arthralgia (PR 2.26, 95\% CI 1.43-3.57) after January 2015, but not for separate episodes of fever or arthralgia (Table 2).

\section{Frequency of Symptomatic Infections among Participants with CHIKV IgG}

Of the 209 participants with detected CHIKV IgG, 32 $(15.3 \%)$ recalled an episode of fever and arthralgia after January 2015. The median duration of arthralgia for these 32 positive participants was 5 (IQR 3-9) days; the longest duration was 60 days for 1 person. Participants with symptomatic infection tended to be older $(p=0.07)$; more frequently reported other clinical manifestations compatible with CHIKV infection, such as myalgia, rash, and pruritus $(\mathrm{p}<0.01$ for each symptom); and more commonly received a presumptive clinical diagnosis of chikungunya or Zika $(\mathrm{p}<0.01$ for both) but not of dengue $(p=0.62)$ (Table 3).

\section{Frequency of Presumptive Clinical Diagnosis of Chikungunya}

Among the 209 participants with a previous CHIKV infection, $24(11.5 \%)$ reported receiving a clinical presumptive diagnosis of chikungunya. Although low, this frequency was 7.5 (95\% CI 4.3-12.9) times greater than the $1.5 \%(24 / 1,563)$ frequency among the participants who were negative for CHIKV IgG $(p<0.01)$. Noteworthy for the $32 \mathrm{CHIKV}$-infected participants who had symptomatic disease, 20 (62.5\%) reported a presumptive clinical diagnosis of chikungunya (Table 3). On the other hand, of the 48 participants who reported having received a clinical presumptive diagnosis of chikungunya, 24 had CHIKV IgG detected, indicating a positive predictive value of $50 \%$ for the presumptive diagnosis.

\section{Frequency of CHIKV IgM}

Among the 209 participants who were positive for CHIKV IgG, 49 (23.4\%) also had CHIKV IgM, possibly indicating a recent infection. We found no associations between sociodemographic or clinical characteristics and the presence of CHIKV IgM (data not shown).

\section{Discussion}

Despite retrospective evidence of a chikungunya outbreak in Salvador during June-November 2015 $(12,15)$, we found that $\approx 2$ years later (November 2016-February 2017), <12\% of the subjects enrolled in this large cross-sectional neighborhood survey had been infected by CHIKV. This seroprevalence is much lower than that found in 3 additional CHIKV serologic surveys performed in Brazil at that time. During November-December 2015, in Feira de Santana, $\approx 100$ $\mathrm{km}$ from Salvador, the prevalence of prior CHIKV infection was estimated at $57.1 \%$; in the urban area of Riachão do Jacuípe, $185 \mathrm{~km}$ from Salvador, prevalence was estimated at $45.7 \%$ (29). In the rural area of Riachão do Jacuípe, the prevalence of prior CHIKV 
infection was 20.0\% in April 2016 (30). It is unlikely that a gradual decrease in the IgG levels over time influenced these differences, because we surveyed the participants relatively soon after the outbreak. Thus, the wide range of prevalence levels in adjacent cities most possibly indicates that the intensity of CHIKV transmission, after its first introduction, may vary greatly even among relatively close locations.

Serum surveys performed in Haiti during December 2014 and February 2015, about 1 year after detection of the index case in the country, also found large variations in the seroprevalence (mean of $78.4 \%$ for the urban sites and $44.9 \%$ for the rural sites) (31). These differences may be related to Aedes spp. infestation levels and diversity, variations in local geographic and climate conditions, the predominant CHIKV strain circulating, and even by interactions when the vector species may be coinfected with CHIKV and other circulating arboviruses, such as ZIKV and DENV. Furthermore, a very localized and self-restricted CHIKV outbreak has been recently described in Salvador (32), which suggests that local environmental characteristics and patterns of human activity and movement in specific regions may be responsible for the emergence of CHIKV and the extent of its spread.

\begin{tabular}{|c|c|c|c|}
\hline \multirow[b]{2}{*}{ Characteristic } & \multicolumn{2}{|c|}{ Disease status of infected participants, no. \%† } & \multirow[b]{2}{*}{$\mathrm{p}$ value } \\
\hline & Symptomatic, $n=32$ & Asymptomatic, $\mathrm{n}=177$ & \\
\hline \multicolumn{4}{|l|}{ Sociodemographic } \\
\hline \multicolumn{4}{|l|}{ Sex } \\
\hline M & $12(37.5)$ & $81(45.8)$ & 0.39 \\
\hline $\mathrm{F}$ & $20(62.5)$ & $96(54.2)$ & \\
\hline \multicolumn{4}{|l|}{ Age, y } \\
\hline $5-14$ & $2(6.3)$ & $40(22.6)$ & 0.07 \\
\hline 15-39 & $22(68.8)$ & $82(46.3)$ & \\
\hline$\geq 40$ & $8(24.9)$ & $55(31.1)$ & \\
\hline \multicolumn{4}{|l|}{ Education $\ddagger$} \\
\hline Illiterate & $1(3.1)$ & $13(7.4)$ & 0.42 \\
\hline Literate & $31(96.9)$ & 163 (92.6) & \\
\hline \multicolumn{4}{|l|}{ Skin color } \\
\hline White & 0 & $10(5.7)$ & NA \\
\hline Nonwhite & $32(100)$ & 167 (94.3) & \\
\hline \multicolumn{4}{|c|}{ Household per capita income, US\$/day $\ddagger$} \\
\hline$\leq 5.50$ & $27(84.4)$ & $144(81.8)$ & 0.73 \\
\hline$>5.50$ & $5(15.6)$ & $32(18.2)$ & \\
\hline \multicolumn{4}{|l|}{ Clinical: reported symptoms } \\
\hline \multicolumn{4}{|l|}{ Fever and arthralgia } \\
\hline None & 0 & $111(62.7)$ & $<0.01$ \\
\hline Only fever & 0 & $39(22.0)^{\prime}$ & \\
\hline Only arthralgia & 0 & $20(11.3)$ & \\
\hline Both, not simultaneous & 0 & $7(4.0)$ & \\
\hline Both, simultaneous & 32 (100) & 0 & \\
\hline \multicolumn{4}{|l|}{ Myalgia } \\
\hline Yes & $18(56.3)$ & $24(13.6)$ & $<0.01$ \\
\hline No & $14(43.7)$ & $153(86.4)$ & \\
\hline \multicolumn{4}{|l|}{ Rash } \\
\hline Yes & $22(68.7)$ & $28(15.9)$ & $<0.01$ \\
\hline No & $10(31.3)$ & $148(84.1)$ & \\
\hline \multicolumn{4}{|l|}{ Pruritus } \\
\hline Yes & $21(65.6)$ & $25(14.1)$ & $<0.01$ \\
\hline No & $11(34.4)$ & $152(85.9)$ & \\
\hline \multicolumn{4}{|l|}{ Presumptive clinical diagnosis } \\
\hline \multicolumn{4}{|l|}{ Chikungunya } \\
\hline Yes & $20(62.5)$ & $12(6.8)$ & $<0.01$ \\
\hline No & $12(37.5)$ & $165(93.2)$ & \\
\hline \multicolumn{4}{|l|}{ Dengue } \\
\hline Yes & $4(12.5)$ & $17(9.6)$ & 0.62 \\
\hline No & $28(87.5)$ & $160(90.4)$ & \\
\hline \multicolumn{4}{|l|}{ Zika } \\
\hline Yes & $18(56.3)$ & $20(11.3)$ & $<0.01$ \\
\hline No & $14(43.7)$ & $157(88.7 \%)$ & \\
\hline
\end{tabular}

${ }^{*} \mathrm{NA}$, not available

†CHIKV disease status was defined as symptomatic on the basis of self-reported fever accompanied by arthralgia after January 2015. ‡Data not available for 1 participant with an asymptomatic CHIKV infection. 
In bivariate analyses, we found that structural deficiencies in the housing and on the streets where the houses were located were associated with previous CHIKV infection, pointing to a social gradient that poses an increased risk for virus exposure among the most vulnerable residents. Urban areas served by unpaved streets and where the walls of houses are not plastered, or made of wood or of other material other than brick, often also lack basic sanitation services, such as regular garbage collection and potable water. These conditions, in turn, influence improper disposal of trash and accumulation of water in containers, both well-known breeding grounds for Aedes mosquitoes.

In addition, low education levels in such settings may limit residents' ability to access, understand, and act on information about measures to prevent mosquitoborne diseases $(33,34)$. Individual- and ecologic-level studies in rural Kenya (35), Nicaragua (36), and Colombia (37) have also showed that socioeconomic vulnerability and living near sites where water accumulates are associated with increased chikungunya incidence.

The widely accepted understanding of CHIKV infection has been that the majority $(>70 \%)$ of infected persons develop a symptomatic form of the disease (1). We, conversely, found a frequency of symptomatic infection, defined by having arthralgia accompanied by fever, of only $15.3 \%$. Other studies have also found low proportions of symptomatic CHIKV infection. In Brazil, serologic surveys estimated the proportion of symptomatic CHIKV infection to be $32.7 \%$ in Feira de Santana and $41.2 \%$ in Riachão do Jacuípe (29). Prospective cohort studies, a more robust study design for determining the natural history of disease, have also found low proportions of symptomatic infections. For example, during a cohort follow-up in the Philippines, the subclinical incidence of CHIKV infection was 10.0 per 100 person-years, while the incidence of symptomatic CHIKV infection was 2.2 per 100 person-years, indicating that $<20 \%$ of those infected exhibited symptoms (38). However, because of the small geographic range of the studies, these findings should be considered limited.

Differences in symptomatic infection rates may be related to the lineage of CHIKV that is circulating $(39,40)$, the diversity in human immunological responses driven by specific genetic characteristics (41), or even by the CHIKV exposure dose delivered by mosquitoes (42). In our study, we found that both women and persons $\geq 15$ years of age were more likely to have symptomatic CHIKV infections than others, but the power of our analyses was limited by the small number of CHIKV infections that we detected. However, our results are in accordance with other studies that suggest that women are at increased risk for symptomatic disease and that risk for symptomatic disease increases with age (29). Further cohort studies are needed to determine the factors that may influence whether the infection becomes symptomatic. We also found that chronic arthralgia after CHIKV infection was uncommon; the maximum reported duration for the articular pain was 60 days, observed in just $1(0.5 \%)$ of the $209 \mathrm{CHIKV}$-infected persons.

On the basis of these findings, we hypothesize that asymptomatic and milder clinical manifestations with less severe arthralgia and low rates of the disease becoming chronic may occur under certain circumstances of CHIKV infection. If further investigation supports this hypothesis, this finding might partially explain the low proportion of participants testing positive for CHIKV who received a correct presumptive diagnosis.

We did find that report of a presumptive clinical diagnosis of chikungunya disease was strongly associated with having CHIKV IgG (positive predictive value of $50 \%$ ). Thus, during and after outbreaks, persons exhibiting CHIKV-associated symptoms and suspected disease should be clinically tested because of the likelihood of having confirmed chikungunya disease.

Our study findings have limitations. First, we surveyed just 1 neighborhood of Salvador and, thus, could not capture potential variations in prior exposure to CHIKV within the city. However, because the community where we conducted the study has poor sanitation infrastructure, which is associated with a higher density of Aedes aegypti mosquitoes, and high population density, associated with greater risk of arboviral transmission, it is unlikely that the CHIKV seroprevalence of the city population overall was much higher than the one we measured in the Pau da Lima community.

Second, we used a commercial CHIKV IgG ELISA to detect previous CHIKV infections. Prior studies have reported high accuracy levels for this test (sensitivity $88 \%-100 \%$, specificity $82 \%-95 \%(43,44)$. In our ELISA retesting of $100 \mathrm{IgG}$ negative samples, we found that cryoglobulinemia likely did not influence our seroprevalence; moreover, we found an excellent agreement between the IgG ELISA and the $\mathrm{PRNT}_{90}$. However, because cryoglobulinemia had been described for CHIKV (45), further surveys should consider this possible effect.

Third, although transmission of other alphaviruses, such as Mayaro and o'nyong-nyong, has not been reported in northeastern Brazil, because we 
did not perform PRNT $_{90}$ for other alphaviruses, we cannot completely rule out the possibility of crossreactions. In addition, it has been shown that IgG seroconversion might not occur or may occur at later stages after CHIKV infection, possibly due to a strong and longlasting CHIKV IgM immune response (46). It is possible that this diagnostic limitation hampered detection of some cases of CHIKV infection, especially those occurring shortly before the survey was conducted.

Fourth, the proportion of symptomatic infections may have been underestimated because of the 2-year gap between the chikungunya outbreak in Salvador and when the study was conducted and because we did not consider those reporting only fever or only arthralgia to have symptomatic disease. Thus, the observed symptomatic rate from our study should be considered a minimum level. Last, the cross-sectional design made it difficult to determine the temporal relation between exposures to risk and occurrence of CHIKV infection.

In summary, our findings suggest that although CHIKV and ZIKV both spread through Salvador in the same year, $2015(12,15,47)$, transmission of CHIKV seems to have been much less intense, reaching $\approx 12 \%$ of the population, compared to estimates of $63 \%-73 \%$ for ZIKV $(22,48)$. Viral competition within hosts and vectors may be a key element in explaining this dynamic. Further comparative studies on immunopathogenesis and vectorial competence are needed to clarify why these 2 arboviruses, transmitted by the same mosquito vectors, presented such different patterns of transmission spread, given that the population was completely naive for both of them.

Our findings also show that other parts of Brazil and the Americas may be largely susceptible to CHIKV transmission. It is thus necessary to maintain surveillance to promptly detect further epidemics and to invest in developing and evaluating target interventions, such as vaccines and novel approaches for vector control, that will help protect the population from CHIKV and other arboviral infections.

\section{Acknowledgments}

We thank the study participants and the community leaders from the Pau da Lima Urban Health Council who provided support for the investigation and the team members from Fundação Oswaldo Cruz (especially Perla Santana, Renan Rosa, Paula Sousa Barbosa, Leile Camila Jacob Nascimento, and Isabele de Pádua Carvalho), who participated in the data collection, laboratory experiments, or provided assistance with data management and administrative matters.
This study was supported by the Brazilian National Council for Scientific and Technological Development (grants 400830/2013-2, 440891/2016-7, and 421522/2016-0 to G.S.R., grant 439967/2016-3 to R.K., and scholarships to M.G.R., U.K., and G.S.R.); the Coordination for the Improvement of Higher Education Personnel, Brazilian Ministry of Education (grant 88887.130746/2016-00 to G.S.R.); the Research Support Foundation for the State of Bahía (grant FAPESB PET0022/2016 to G.S.R.); the US National Institutes of Health (grants NIAID 5 R01 AI121207, FIC 5 R01 TW009504, FIC 5 R25 TW009338, and NIAID 5 U01 AI088752 to A.I.K.); the Wellcome Trust (102330/Z/13/Z to F.C.); the Yale School of Public Health; the Oswaldo Cruz Foundation; the Federal University of Bahia; and the Department of Science and Technology, Secretariat of Science, Technology and Strategic Inputs, Brazilian Ministry of Health.

\section{About the Author}

Ms. Anjos is a nurse with a master of science degree and is a PhD candidate at the Fundação Oswaldo Cruz, Salvador, Brazil. Her primary research interests are epidemiology of arboviruses and infectious diseases of global relevance.

\section{References}

1. Weaver SC, Lecuit M. Chikungunya virus and the global spread of a mosquito-borne disease. N Engl J Med. 2015;372:1231-9. https:/ / doi.org/10.1056/NEJMra1406035

2. Thiberville SD, Moyen N, Dupuis-Maguiraga L, Nougairede A, Gould EA, Roques P, et al. Chikungunya fever: epidemiology, clinical syndrome, pathogenesis and therapy. Antiviral Res. 2013;99:345-70. https://doi.org/ 10.1016/j.antiviral.2013.06.009

3. Fischer M, Staples JE, Arboviral Diseases Branch, National Center for Emerging and Zoonotic Infectious Diseases, CDC. Chikungunya virus spreads in the Americas - Caribbean and South America, 2013-2014. MMWR Morb Mortal Wkly Rep. 2014;63:500-1.

4. Gallian P, Leparc-Goffart I, Richard P, Maire F, Flusin O, Djoudi R, et al. Epidemiology of chikungunya virus outbreaks in Guadeloupe and Martinique, 2014: an observational study in volunteer blood donors. PLoS Negl Trop Dis. 2017;11:e0005254. https:// doi.org/10.1371/ journal.pntd.0005254

5. Sharp TM, Roth NM, Torres J, Ryff KR, Rodríguez NMP, Mercado C, et al. Chikungunya cases identified through passive surveillance and household investigations - Puerto Rico, May 5-August 12, 2014. MMWR Morb Mortal Wkly Rep. 2014;63:1121-8.

6. Hennessey MJ, Ellis EM, Delorey MJ, Panella AJ, Kosoy OI, Kirking HL, et al. Seroprevalence and symptomatic attack rate of chikungunya virus infection, United States Virgin Islands, 2014-2015. Am J Trop Med Hyg. 2018;99:1321-6. https://doi.org/10.4269/ajtmh.18-0437

7. Nunes MRT, Faria NR, de Vasconcelos JM, Golding N, Kraemer MU, de Oliveira LF, et al. Emergence and potential for spread of chikungunya virus in Brazil. BMC Med. 2015;13:102. https://doi.org/10.1186/s12916-015-0348-x 
8. Teixeira MG, Andrade AMS, Costa MC, Castro JN, Oliveira FLS, Goes CSB, et al. East/Central/South African genotype chikungunya virus, Brazil, 2014. Emerg Infect Dis. 2015;21:906-7. https:// doi.org/10.3201/eid2105.141727

9. Secretaria de Vigilância em Saúde/Ministério da Saúde. Monitoring of cases of dengue, chikungunya fever and fever by the Zika virus until epidemiological week 49, 2016 [in Portuguese]. Vol. 47, Boletim Epidemiológico. 2016 [cited 2018 Dec 23]. https://www.saude.gov.br/images/ pdf/2016/dezembro/20/2016-033---Dengue-SE49publicacao.pdf

10. Secretaria de Vigilância em Saúde/Ministério da Saúde. Monitoring of cases of dengue, chikungunya fever and fever by the Zika virus until epidemiological week 35, 2017 [In Portuguese]. Vol. 48, Boletim Epidemiológico. 2017 [cited 2018 Dec 23]. https:/ / www.saude.gov.br/images/ pdf/2017/setembro/15/2017-028-Monitoramento-dos-casosde-dengue--febre-de-chikungunya-e-febre-pelo-virus-Zikaate-a-Semana-Epidemiologica-35.pdf

11. Secretaria de Vigilância em Saúde/Ministério da Saúde. Monitoring of cases of dengue, chikungunya fever and fever by the Zika virus until epidemiological week 43, 2018 [in Portuguese]. Vol. 49, Boletim Epidemiológico. 2018 [cited 2018 Dec 23]. http:/ / portalarquivos2.saude.gov.br/images/ pdf/2018/novembro/13/2018-056.pdf

12. Cardoso CW, Kikuti M, Prates APPB, Paploski IAD, Tauro LB, Silva MMO, et al. Unrecognized emergence of chikungunya virus during a Zika virus outbreak in Salvador, Brazil. PLoS Negl Trop Dis. 2017;11:e0005334. https://doi.org/10.1371/journal.pntd.0005334

13. de Oliveira WK, Carmo EH, Henriques CM, Coelho G, Vazquez E, Cortez-Escalante J, et al. Zika virus infection and associated neurologic disorders in Brazil. N Engl J Med. 2017;376:1591-3. https:/ / doi.org/10.1056/NEJMc1608612

14. Instituto Brasileiro de Geografia e Estatística. Brazil/Bahia/ Salvador. 2018 [cited 2019 Jun 5]. https:/ / cidades.ibge.gov. $\mathrm{br} / \mathrm{brasil} / \mathrm{ba} /$ salvador/panorama

15. Silva MMO, Tauro LB, Kikuti M, Anjos RO, Santos VC, Gonçalves TSF, et al. Concomitant transmission of dengue, chikungunya and Zika viruses in Brazil: clinical and epidemiological findings from surveillance for acute febrile illness. Clin Infect Dis. 2019;69:1353-9. https://doi.org/10.1093/cid/ciy1083

16. Kikuti M, Cunha GM, Paploski IAD, Kasper AM, Silva MM, Tavares AS, et al. Spatial distribution of dengue in a Brazilian urban slum setting: role of socioeconomic gradient in disease risk. PLoS Negl Trop Dis. 2015;9:e0003937. https://doi.org/10.1371/journal.pntd.0003937

17. Reis RB, Ribeiro GS, Felzemburgh RDM, Santana FS, Mohr S, Melendez AXTO, et al. Impact of environment and social gradient on Leptospira infection in urban slums. PLoS Negl Trop Dis. 2008;2:e228. https:/ / doi.org/10.1371/journal.pntd.0000228

18. Felzemburgh RDM, Ribeiro GS, Costa F, Reis RB, Hagan JE, Melendez AXTO, et al. Prospective study of leptospirosis transmission in an urban slum community: role of poor environment in repeated exposures to the Leptospira agent. PLoS Negl Trop Dis. 2014;8:e2927. https:/ / doi.org/10.1371/ journal.pntd.0002927

19. Hagan JE, Moraga P, Costa F, Capian N, Ribeiro GS, Wunder EA Jr, et al. Spatiotemporal determinants of urban leptospirosis transmission: four-year prospective cohort study of slum residents in Brazil. PLoS Negl Trop Dis. 2016;10:e0004275. https://doi.org/10.1371/ journal.pntd.0004275

20. Rodriguez-Barraquer I, Costa F, Nascimento EJM, Nery N, Castanha PMS, Sacramento GA, et al. Impact of preexisting dengue immunity on Zika virus emergence in a dengue endemic region. Science. 2019;363:607-10. https://doi.org/ $10.1126 /$ science.aav6618

21. Silva MM, Rodrigues MS, Paploski IA, Kikuti M, Kasper AM, Cruz JS, et al. Accuracy of dengue reporting by national surveillance system, Brazil. Emerg Infect Dis. 2016;22:336-9. https:// doi.org/10.3201/eid2202.150495

22. Unger A, Felzemburgh RDM, Snyder RE, Ribeiro GS, Mohr S, Costa VBA, et al.; Pau da Lima Urban Health Team. Hypertension in a Brazilian urban slum population. J Urban Health. 2015;92:446-59. https://doi.org/10.1007/ s11524-015-9956-1

23. Snyder RE, Rajan JV, Costa F, Lima HCAV, Calcagno JI, Couto RD, et al. Differences in the prevalence of noncommunicable disease between slum dwellers and the general population in a large urban area in Brazil. Trop Med Infect Dis. 2017;2:47. https:/ / doi.org/10.3390/ tropicalmed2030047

24. Harvey LA. REDCap: web-based software for all types of data storage and collection. Spinal Cord. 2018;56:625. https://doi.org/10.1038/s41393-018-0169-9

25. Baer A, Kehn-Hall K. Viral concentration determination through plaque assays: using traditional and novel overlay systems. J Vis Exp. 2014; (93):e52065. https:/ / doi.org/ $10.3791 / 52065$

26. Kolopp-Sarda MN, Miossec P. Cryoglobulins: an update on detection, mechanisms and clinical contribution. Autoimmun Rev. 2018;17:457-64. https://doi.org/10.1016/ j.autrev.2017.11.035

27. World Bank. Piecing together the poverty puzzle. 2018 [cited 2018 Dec 21]. https:/ / openknowledge.worldbank.org/ bitstream/handle/10986/30418/9781464813306.pdf

28. StataCorp. Stata Statistical Software: release 14. College Station (TX): StataCorp LP. 2015 [cited 2018 Sep 30]. https://www.stata.com

29. Dias JP, Costa MCN, Campos GS, Paixao ES, Natividade MS, Barreto FR, et al. Seroprevalence of chikungunya virus after its emergence in Brazil. Emerg Infect Dis. 2018;24:617-24. https://doi.org/10.3201/eid2404.171370

30. Cunha RV, Trinta KS, Montalbano CA, Sucupira MVF, de Lima MM, Marques E, et al. Seroprevalence of chikungunya virus in a rural community in Brazil. PLoS Negl Trop Dis. 2017;11:e0005319. https:// doi.org/10.1371/ journal.pntd.0005319

31. Rogier EW, Moss DM, Mace KE, Chang M, Jean SE, Bullard SM, et al. Use of bead-based serologic assay to evaluate chikungunya virus epidemic, Haiti. Emerg Infect Dis. 2018;24:995-1001. https:// doi.org/10.3201/eid2406.171447

32. Tauro LB, Cardoso CW, Souza RL, Nascimento LC, Santos DRD, Campos GS, et al. A localized outbreak of chikungunya virus in Salvador, Bahia, Brazil. Mem Inst Oswaldo Cruz. 2019;114:e180597. https:/ / doi.org/ 10.1590/0074-02760180597

33. Higuera-Mendieta DR, Cortés-Corrales S, Quintero J, González-Uribe C. KAP surveys and dengue control in Colombia: disentangling the effect of sociodemographic factors using multiple correspondence analysis. PLoS Negl Trop Dis. 2016;10:e0005016. https://doi.org/10.1371 /journal.pntd.0005016

34. Whiteman A, Mejia A, Hernandez I, Loaiza JR. Socioeconomic and demographic predictors of resident knowledge, attitude, and practice regarding arthropodborne viruses in Panama. BMC Public Health. 2018;18:1261. https:/ / doi.org/10.1186/s12889-018-6172-4

35. Grossi-Soyster EN, Cook EAJ, de Glanville WA, Thomas LF, Krystosik AR, Lee J, et al. Serological and spatial analysis of 
alphavirus and flavivirus prevalence and risk factors in a rural community in western Kenya. PLoS Negl Trop Dis. 2017;11:e0005998. https://doi.org/10.1371/ journal.pntd.0005998s

36. Kuan G, Ramirez S, Gresh L, Ojeda S, Melendez M, Sanchez N, et al. Seroprevalence of anti-chikungunya virus antibodies in children and adults in Managua, Nicaragua, after the first chikungunya epidemic, 2014-2015. PLoS Neg1 Trop Dis. 2016;10:e0004773. https:// doi.org/10.1371/ journal.pntd.0004773

37. Krystosik AR, Curtis A, Buritica P, Ajayakumar J, Squires R, Dávalos D, et al. Community context and sub-neighborhood scale detail to explain dengue, chikungunya and Zika patterns in Cali, Colombia. PLoS One. 2017;12:e0181208. https://doi.org/10.1371/journal.pone.0181208

38. Yoon I-K, Alera MT, Lago CB, Tac-An IA, Villa D, Fernandez S, et al. High rate of subclinical chikungunya virus infection and association of neutralizing antibody with protection in a prospective cohort in the Philippines. PLoS Negl Trop Dis. 2015;9:e0003764. https://doi.org/10.1371/ journal.pntd.0003764

39. Teo T-H, Her Z, Tan JJL, Lum F-M, Lee WWL, Chan Y-H, et al. Caribbean and La Réunion chikungunya virus isolates differ in their capacity to induce proinflammatory Th1 and NK cell responses and acute joint pathology. J Virol. 2015;89:7955-69. https://doi.org/10.1128/JVI.00909-15

40. Langsjoen RM, Haller SL, Roy CJ, Vinet-Oliphant H, Bergren NA, Erasmus JH, et al. Chikungunya virus strains show lineage-specific variations in virulence and cross-protective ability in murine and nonhuman primate models. MBio. 2018;9:e02449-17. https://doi.org/10.1128/ mBio.02449-17

41. Chaaithanya IK, Muruganandam N, Anwesh M, Rajesh R, Ghosal SR, Kartick C, et al. HLA class II allele polymorphism in an outbreak of chikungunya fever in Middle Andaman, India. Immunology. 2013;140:202-10. https:/ / doi.org/ 10.1111/imm. 12128

42. Gordon A, Gresh L, Ojeda S, Chowell G, Gonzalez K, Sanchez N, et al. Differences in transmission and disease severity between 2 successive waves of chikungunya. Clin Infect Dis. 2018;67:1760-7. https://doi.org/10.1093/ cid/ciy356

43. Prat CM, Flusin O, Panella A, Tenebray B, Lanciotti R, Leparc-Goffart I. Evaluation of commercially available serologic diagnostic tests for chikungunya virus. Emerg Infect Dis. 2014;20:2129-32. https:/ / doi.org/10.3201/ eid2012.141269

44. De Salazar PM, Valadere AM, Goodman CH, Johnson BW. Evaluation of three commercially-available chikungunya virus immunoglobulin G immunoassays. Rev Panam Salud Publica. 2017;41:e62. https:/ / doi.org/10.26633/ RPSP.2017.62

45. Oliver M, Grandadam M, Marimoutou C, Rogier C, Botelho-Nevers E, Tolou H, et al. Persisting mixed cryoglobulinemia in chikungunya infection. PLoS Negl Trop Dis. 2009;3:e374. https:/ / doi.org/10.1371/ journal.pntd.0000374

46. Bozza FA, Moreira-Soto A, Rockstroh A, Fischer C, Nascimento AD, Calheiros AS, et al. Differential shedding and antibody kinetics of Zika and chikungunya viruses, Brazil. Emerg Infect Dis. 2019;25:311-5. https:// doi.org/10.3201/eid2502.180166

47. Cardoso CW, Paploski IAD, Kikuti M, Rodrigues MS, Silva MMO, Campos GS, et al. Outbreak of exanthematous illness associated with Zika, chikungunya, and dengue viruses, Salvador, Brazil. Emerg Infect Dis. 2015;21:2274-6. https://doi.org/10.3201/eid2112.151167

48. Netto EM, Moreira-Soto A, Pedroso C, Höser C, Funk S, Kucharski AJ, et al. High Zika virus seroprevalence in Salvador, Northeastern Brazil limits the potential for further outbreaks. MBio. 2017;8:e01390-407. https:// doi.org/ 10.1128/mBio.01390-17

Address for correspondence: Guilherme Sousa Ribeiro. Instituto Gonçalo Moniz, Fundação Oswaldo Cruz, Rua Waldemar Falcão, 121, Candeal, 40296-710 Salvador, BA, Brazil; email: guilherme.ribeiro@bahia.fiocruz.br 